\title{
Ambulatory patients with coronavirus disease-19
}

\author{
Francisco P. Navarro-Reynoso* and Benito Vargas-Abrego \\ Pneumology and Thoracic Surgery Service, Hospital General de México, Dr. Eduardo Liceaga. Mexico City, Mexico
}

\begin{abstract}
In 2020, we are living one of the most severe pandemics in history. A virus is able to generate alterations such as inflammation, viral replication, plungers in the pulmonary circuit, and low T lymphocytes, affecting hemodynamics and gas exchange, so that the patient has a clinical state of gravity. In the present work, we present a group of patients managed from home, we monitored some variables with medical equipment and clinical parameters directly and indirectly, for the high demands of hospitalization and based on the criteria of international protocols.
\end{abstract}

Key words: Coronavirus disease-19. Ambulatory management. Coronavirus disease-19 pandemic.

\section{Introduction}

The global pandemic of 2020 caused by the severe acute respiratory syndrome coronavirus 2 (SARSCoV)-2, which generates the disease named coronavirus disease (COVID)-19, has challenged all the sanitary systems of the world since its apparition in Wuhan, China. Until July 30, 2020, it has been reported more than 17 million of positive cases and more than 667 thousand deaths in more than 200 countries. This virus is similar than the one described on SARS-CoV and Middle East respiratory syndrome-related coronavirus epidemics. Animals are intermediate reservoirs between humans ${ }^{1,2}$.

We have observed since January of 2020 that the information has changed through the days and weeks. Therefore, what we write today could not be valid tomorrow.

We present a group of ambulatory patients treated by our team, considering the experience acquired by physicians from China, France, Spain, and some other countries of Europe. We revised several treatments and alterations present in this disease ${ }^{3}$.

\section{Clinical cases}

We present a series of cases treated on an outpatient basis with COVID-19 clinical data. Almost all of them had a real-time polymerase chain reaction (PRC) for detecting SARS-CoV-2. It is a group of 371 consecutive patients attended in an outpatient basis from March 17, 2020 , to May 31, 2020. Ages varied from 17 to 78 years of age with a mean of 42 years. There were 119 women and 252 men (Table 1).

All the patients that assisted to consultation referred a sense of general malaise, asthenia and adynamia (100\%); temperature above $37^{\circ} \mathrm{C}(80 \%)$; chills $(76 \%)$; mild or severe headache $(74 \%)$; sore throat $(72 \%)$; dry cough (70\%); sore muscles (70\%); ageusia and anosmia, verified using a special set of odors and flavors (45\%); and diarrheic syndrome (10\%) (Fig. 1).

\section{Correspondence:}

${ }^{*}$ Francisco P. Navarro-Reynoso

E-mail: franciscopnavarro@yahoo.com.mx BY-NC-ND license (http://creativecommons.org/licenses/by-nc-nd/4.0/).

Available online: 16-10-2020 Rev Med Hosp Gen Mex. 2020;83(4):176-181 www.hospitalgeneral.mx 
Table 1. Demographic features of 371 COVID-19 patients treated with ambulatory management

\begin{tabular}{|c|c|}
\hline Demographic features & \\
\hline $\begin{array}{l}\text { Gender } \\
\text { Women } \\
\text { Men }\end{array}$ & $\begin{array}{l}] 119 \\
252\end{array}$ \\
\hline $\begin{array}{l}\text { Age } \\
\text { Age interval } \\
\text { Mean }\end{array}$ & $\begin{array}{c}17 \text { a } 78 \\
42\end{array}$ \\
\hline $\begin{array}{l}\text { Mexican state of precedence } \\
\text { CDMX } \\
\text { Estado de México } \\
\text { Morelos } \\
\text { Veracruz } \\
\text { Guerrero } \\
\text { Sinaloa } \\
\text { Puebla } \\
\text { Guanajuato } \\
\text { Oaxaca } \\
\text { Jalisco } \\
\text { Sonora } \\
\text { Chiapas }\end{array}$ & $\begin{array}{c}188 \\
126 \\
11 \\
11 \\
9 \\
9 \\
6 \\
3 \\
3 \\
2 \\
2 \\
1\end{array}$ \\
\hline $\begin{array}{l}\text { Reference } \\
\text { Other patients } \\
\text { Other physicians }\end{array}$ & $\begin{array}{l}85 \\
15\end{array}$ \\
\hline $\begin{array}{l}\text { Method of interview } \\
\text { Physical consultation } \\
\text { Call (Telephone or Video call) }\end{array}$ & $\begin{array}{l}72 \% \\
28 \%\end{array}$ \\
\hline $\begin{array}{l}\text { Travel to another country } \\
\text { Spain } \\
\text { United States of America } \\
\text { China }\end{array}$ & $\begin{array}{l}8 \\
8 \\
2\end{array}$ \\
\hline $\begin{array}{l}\text { Risk factors } \\
\text { Under the age of } 60 \\
\text { Obesity } \\
\text { Diabetes } \\
\text { Older than } 60 \\
\text { Systemic arterial hypertension } \\
\text { Chronic kidney disease }\end{array}$ & $\begin{array}{c}68 \% \\
65 \% \\
42 \% \\
32 \% \\
26 \% \\
6 \%\end{array}$ \\
\hline
\end{tabular}

On physical examination, we identified conjunctivitis (54\%); pharyngeal redness (72\%); decrease of breathing movements (44\%); sweaty skin, temperature above $37^{\circ} \mathrm{C}$, and oxygen saturation below $90 \%$ but $>83 \%$ (20\%); fine-crackling rales (26\%); abdominal pain $(23 \%)$; expiratory wheeze $(15 \%)$; and livedo reticularis $(10 \%)$. A special finding that we want to report is that we noted hyperemia over the uvula with a vascular increase in more than $50 \%$ of the patients with COVID-19 (Figs. 1 and 2).

Chest X-ray films were found normal in $6 \%$ of the cases, ground-glass opacities in $73 \%$. Simple computer tomography was done in the same patients, finding sub segmentary images, ground-glass opacities, and consolidated images inside the ground-glass opacities

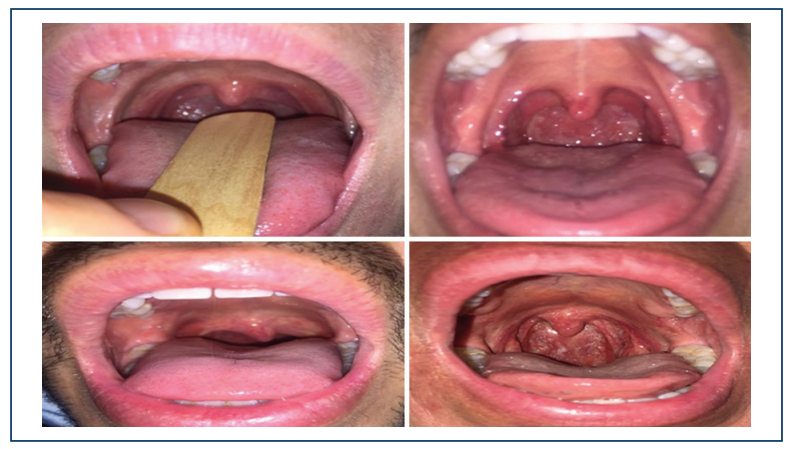

Figure 1. Reticular vessels increase found over the uvula in patients with coronavirus disease-19.

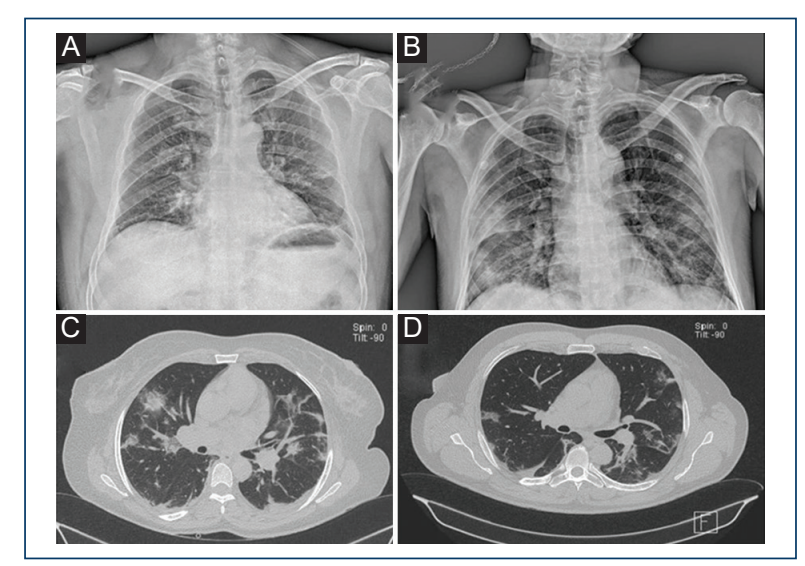

Figure 2. A: chest X-ray film with bilateral patchy and ground-glass opacities. B: chest film with bilateral, reticular, patchy, and ground-glass opacities and intercisural pleural effusion. C: simple thorax tomography with ground-glass opacities, some of them patchy, bilateral, and some of them triangular with inner vertex and external base. D: thorax tomography with a pulmonary window showing ground-glass opacities, patchy, triangular-shaped with external base and inner vertex.

in some of them. All the lesions were bilateral and had several sizes; some images had triangle shapes with internal vertex and external base. Minimum pleural effusion was found in $22 \%$ of the patients (Fig. 2).

Rapid influenza and COVID-19 tests were carried out in 174 of 371 patients, resulting negative for influenza in 169 cases. Three hundred and twenty COVID-19 tests were positive and 48 negative. All COVID-19 negative test patients had a clinical course compatible with this disease. Three patients were not tested for COVID-19 because they did not want to wait 10 days without treatment until they had the results.

The most important findings in laboratory tests were leucopenia from 2.5 to $3.4 \times 10 \mathrm{e} 3 / \mathrm{uL}$, neutrophilia and initial lymphopenia and elevated $\mathrm{C}$-reactive protein 


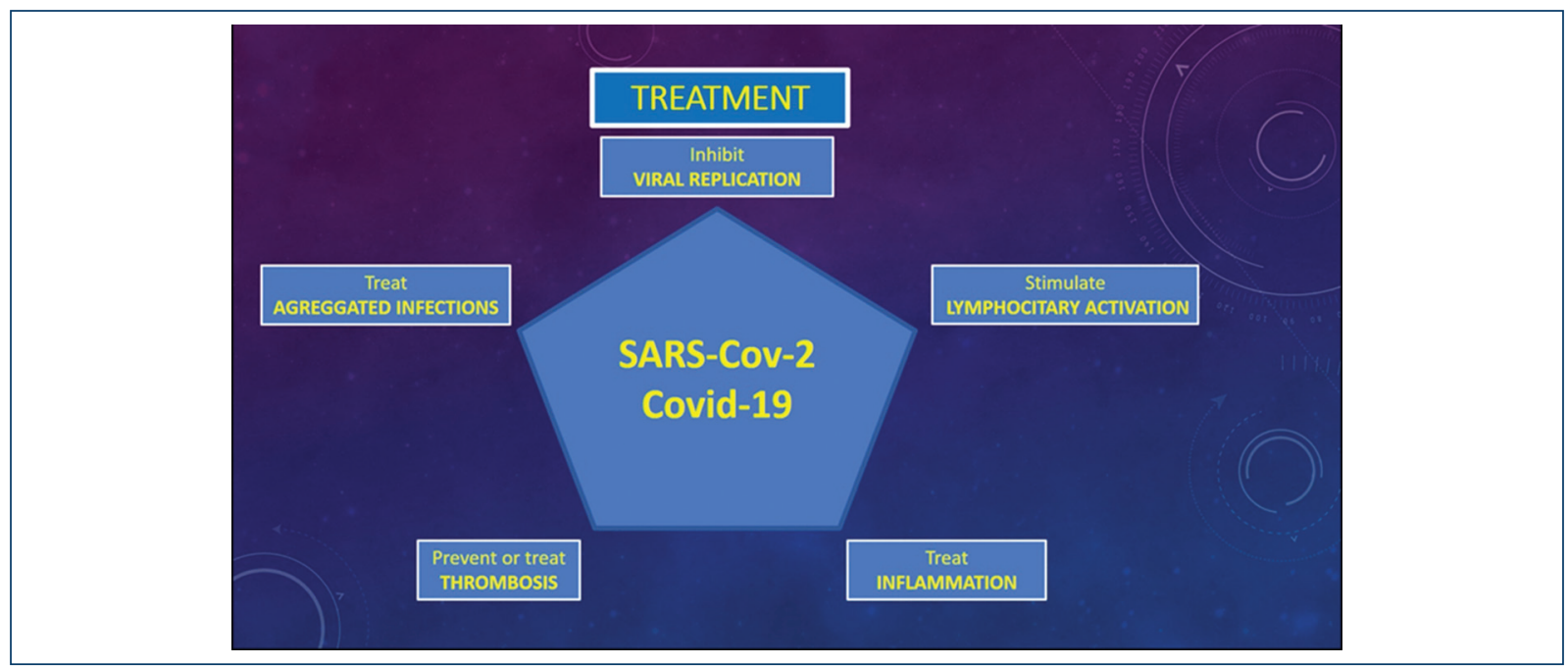

Figure 3. Pentagon proposes the five most important aspects of managing patients with coronavirus disease-19.

Table 2. Treatment scheme used in 371 patients with COVID-19

\begin{tabular}{|l|c|}
\hline Treatment scheme used & \\
\hline $\begin{array}{l}\text { Hydroxychloroquine, azithromycin, ivermectin, } \\
\text { famotidine, and zinc }\end{array}$ & $78 \%$ \\
\hline $\begin{array}{l}\text { Oseltamivir, ivermectin, azithromycin, and famotidine } \\
\text { Amoxicillin/clavulanate }\end{array}$ & $22 \%$ \\
\hline Prednisone & $18 \%$ \\
\hline $\begin{array}{l}\text { Drugs used in hospitalized patients } \\
\text { Tocilizumab } \\
\text { Dexametasona }\end{array}$ & $60 \%$ \\
\hline
\end{tabular}

All these schemes were given according to the current literature reported in China, Australia, and Europe.

(CRP) in 318 patients. Ferritin levels were normal in 27 patients and elevated in 310; procalcitonin levels were slightly elevated in 41 cases; D-dimer level was $>500 \mathrm{ug} / \mathrm{L}$ in 152 cases.

Oral temperature $>37^{\circ} \mathrm{C}$ was present in 330 patients and between 36 and $37^{\circ}$ in 41 patients at the time of physical examination. Only eight patients of the series, hospitalized were intubated. Two patients with the chronic obstructive pulmonary disease died and the rest recovered.

Today we know that there is no effective therapy for this SARS-CoV-2; however, we have adopted the experience that China, Korea, Italy, Spain, and France have accumulated in the management of these patients. We analyzed preliminary communications of the use of drugs against SARS-CoV-2 with the analysis of the physiopathology that initially was unknown; the FDA has not approved many drugs due to the lack of clinical essays $\mathbf{s}^{1,2,4,5}$.

Based on the information above, the first four cases were treated with oseltamivir $75 \mathrm{mg}$ BID during 10 days and Clarithromycin $500 \mathrm{mg}$ BID for 7 days. These patients had symptoms compatible with COVID-19 and had a test, but the waiting time for receiving the results used to last approximately 10 days. We did not consider prescription of remdesivir or lopinavir/ritonavir because of the high price and low availability. Up to March 15, 2020, we considered the combination of azithromycin $500 \mathrm{mg}$ once per day during 7 days and hydroxychloroquine sulfate $400 \mathrm{mg}$ initially and then $200 \mathrm{mg}$ BID for 7 days. We also considered stimulating the action of $\mathrm{T}$ lymphocytes using ivermectin (IVM), based in the management of the alterations observed in the disease (Fig. 3 and Table 2) ${ }^{6-10}$.

All the cases, in which we prescribed hydroxychloroquine sulfate combined with azithromycin, underwent an electrocardiogram to evaluate the QT interval and calculating the corrected QT interval using Bazett's formula: results of dividing the value of the QT interval over the square root of the RR interval. The decision of being able to administer the drug was made only if the value was favorable ${ }^{11-18}$

We indicated half of a milligram per kilogram of prednisone per day from day 5 of treatment, during 20 days, based on their radiological images, and if the dyspnea persisted, evaluating the reduction of the doses gradually according to their radiological evolution. 
Of the group studied, 158 patients coursed with hypertension and received angiotensin-converting enzyme inhibitors (ACE inhibitors) without suspending their treatment according to the reports in the literature ${ }^{1}$. All the patients studied in this series, evolved favorably. Two hundred seventy-four cases were SARSCoV-2 tested after 10 days of initiating treatment, resulting positive only in two cases that required secondary treatment.

At follow-up, 127 patients persisted with an oral temperature between 37 and $37.3^{\circ} \mathrm{C}$ and normalized after 21 days. The remaining symptoms, such as headache, disappeared after 18 days of treatment. Five patients were admitted to the intensive care unit due to respiratory insufficiency and needed intubation. They had elevated D-dimer, Type B atrial natriuretic peptide, erythrocyte sedimentation rate, ferritin, lactic dehydrogenase, CRP, and procalcitonin.

Two patients that received hydroxychloroquine sulfate and azithromycin reported long QT syndrome and needed suspension only of azithromycin but completed treatment only with hydroxychloroquine. Alterations in chest X-ray films normalized in 345 cases and the rest is currently in resolution or formation of fibrosis in certain volumes of the lungs. Two cases formed minimal pleural effusion. In the cases where the SARS-CoV2 PRC test resulted negative, but the patients presented the compatible clinical course, we prescribed the treatment scheme, trying to contribute to decrease the evolution of the disease, as done in other countries. Follow-up was carried out in all patients with phone calls, up to 3 times a day. We asked the patients to report oximetry readings in each call. We found a way to send home a radiologist technician to take chest $\mathrm{X}$-ray films as needed in many of the patients. All the patients had access to means of communication and private laboratory services.

\section{Discussion}

The most important aspect of our discussion is that, of the PCR negative cases that we have treated, almost $50 \%$ have symptoms. Given the severity of these patients or the presence of symptoms, although they had only a few, we administered treatment, observing a non-progressive disease to greater severity. We noted the gradual disappearance of the clinical and radiological signs and symptoms. The presence of a negative test is not conclusive ${ }^{1,2,19}$; however, positive test in patients with clinical history supports the diagnosis. The
Table 3. CURB-65 score for evaluating the severity of COVID-19 patients, adapted from community-acquired pneumonia severity score

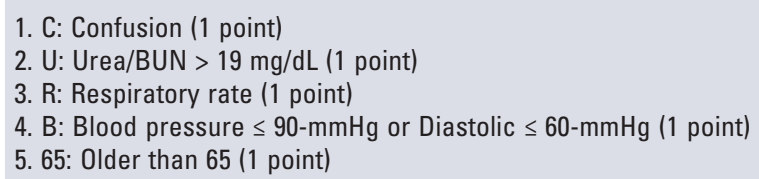

0 points

1 point

2 points

3 points

405 points
0.6

2.7

6.8

14.0

27.8
Low risk; consider ambulatory treatment

Moderate risk: short hospitalization or ambulatory treatment with strict follow-up

Severe pneumonia: hospitalization and consider intensive care admission problem that we have detected is the time that the results of the tests take, with the urgent need to start treatment, as we managed the patients in the present report.

Real-time PCR test for detecting SARS-CoV-2 RNA specific sequences is the most valid way to detect infected patients, being the most sensitive test available nowadays. In our country, it is difficult to know the most accurate number of cases since our leaders have decided to use the Sentinel model for detecting positive cases, leading us to a distant real number of cases detected. Using this model, we can only have partial information of the total number of cases, resulting in the wrong decisions. The experience of other countries that makes a greater number of tests leads to decisions with better basis $\mathbf{s}^{1,2,19}$.

The measurement of oxygen saturation orientates the clinician about the consequences of lung alterations; therefore, it is necessary on decision-making. Oximetry allows monitoring the patient from home and translates one of the best parameters to evaluate the disease. We can also monitor temperature, dyspnea, and general malaise. We can revise the patient from home and indicate laboratory and image studies too $0^{1,2,13,14,20,21}$.

The signs found over the uvula have been described along with other ones in the skin and teguments and most be considered when exploring the patients.

Ground-glass opacities or patchy images seen, both in radiographic images and simple tomography, called our attention due to the observed differences in the studies taken in the patients during the influenza AH1N1 pandemic ${ }^{1-5,20}$. 
We recommend oseltamivir especially in those cases with a clinical course that has symptoms similar than flu disease, and even though its use is still currently discussed, we recommend to prescribe it since it has been described the coexistence of influenza and SARS-CoV-2 $2^{2}$.

Prescription of hydroxychloroquine/azithromycin is very useful, and we suggest to take an electrocardiogram trace paying attention on DII and V5 electrodes to evaluate the QT interval and subsequently, correct the QT interval using the Bazett's formula that results of dividing the value of QT over the square root of the RR interva ${ }^{11}$. Nowadays, and after considering several references, we propose the management showed in figure 3 and table 2, as long as considering CURB-65 severity scale $(\text { Table } 3)^{8}$. Remdesivir can be prescribed since there are several series that support its use; however, the cost could not be accessible to everyone'.

There are not evidences that support the suspension of ACE inhibitors.

The use of corticosteroids is controversial in this and other infectious diseases that affect the lungs; however, it is difficult to establish the best moment of its use ${ }^{21-24}$. In patients with severe pneumonitis due to SARSCoV-2, tocilizumab combined with steroids could be beneficial since the patients with COVID-19 have elevated levels of pro-inflammatory cytokines such as interleukin 1 and 6 (IL-1, IL-6).

IVM is an intra-intestinal and extra-intestinal, anti-parasite drug used in humans and animals. However, since 1991, Blakely and Roisseaux made an essay where the effect of IVM over the increase in the response of T-cell dependent antibodies was evaluated. The function of $T$ lymphocytes improved as long as inhibition of viral replication and its possible application in different degrees of immunosuppression 5-10,23,24.

It is known that inflammation causes hypersecretion of ferritin. SARS-CoV-2 virus has a tropism for the porphyrin group of hemoglobin and can destroy or denaturalize it, bringing consequently an incapacity of the hemoglobin to bind oxygen at the lungs and liberate it in the cells or in the periphery. If this phenomenon remains in the lungs, an intra-alveolar diffuse hemorrhage with severe blockage of the diffusion of oxygen from the alveoli to the lung capillaries can occur 5 .

There are several clinical essays and protocols worldwide recently in search of different treatments for different clinical stages of COVID-19. Some of them with the intention of improving the oxygenation in intubated patients. There are proposals for using nebulized fibrinolytics such as nebulized tissue plasminogen activator or nebulized Dornase alfa, but they are expensive and with low availability. In addition, a protocol considers the use of nebulized heparin combined with acetylcysteine. The theoretical fundament proposes that SARS-CoV-2 has a spike-like protein on its surface that binds heparin and therefore prevents its replication.

There are multiple causes and pathophysiological mechanisms. The approach requires medical equipment and multidisciplinary health professionals with a personalized focus in the diagnosis and treatment of the COVID-19 patient (Fig. 3) $)^{5,20}$.

Reviewing the literature, in autopsies made in 15 patients that died because of influenza in 2009, the most relevant findings were lymphocyte infiltration predominantly in the interstitium, pneumocyte type II hyperplasia with hyaline membranes that obstruct the diffusion of gases, mucus plugs that obstruct the bronchioles lumen and $\mathrm{acini}^{3}$. In autopsies performed on deceased patients for COVID-19, scarce or absent lymphocytary infiltrate was found in the interstice. There was a prevalence of underlying infiltrate in middle lumen vessels, diffuse alveolar damage with fibrin in the alveolar spaces, minimal inflammation, and squamous metaplasia. Attention was brought to the absence of mucus plugs in bronchi or acini, as long as perivascular inflammatory infiltrates in the median lumen vessels, where some microthrombi were found. This supports the theory that some groups argue that patients died because of heart failure and multiple emboli in small lumen vessels. Patients with COVID-19 have a greater risk of venous thromboembolic disease (VTED).

Pregnant women are part of a group in enhanced risk of VTED, in the case of infection for COVID-19, require a more emphatic evaluation in the pregnancy and puerperium ${ }^{1,24-30}$.

One of the questions that remain unanswered is: Why do some of the patients produce a lot of inflammation and some others not? There is not much mentioned about it, but we will have to analyze what individual aspects have influence over inflammation.

We believe that it is important to activate the health virtuous quadrangle, where public and private institutions, government, and society interact in favor of the health and contribute to the best management of the disease ${ }^{17}$.

The pathogenic power of the virus and the alterations that causes can be summarized in five types: 1. increase of viral replication; 2 . aggregated infection; 3. development of thrombi in the territory of the pulmonary artery; 4. pulmonary inflammation; and 5. decrease of the lymphocytary function. Therefore, the treatment 
most be directed to inhibit viral replication with its possible viral destruction; treat the aggregated infection; treat and prevent the development of thrombosis in the pulmonary vascular bed; decrease lung inflammation; and reactivate lymphocyte function. These points above summarize broadly the effects that cause SARS-CoV-2 and being so diverse; the management has to be with more than one drug (Fig. 3).

In a future study, we will separate the patients in terms of different treatments to evaluate particular results. Since no specific treatment is available today for SARS-CoV-2, and due to the severity of the disease, ethical committees must study any prescribed drug in research protocols, peer reviewed, and revised. We know that the treatment that we have proposed is useful to treat the alterations that the virus causes but does not eliminate the virus.

In this disease, what is valid today tomorrow perhaps will not, but what we have today is the only thing we have.

\section{Acknowledgments}

The author thanks to Dr. Benito Vargas for his cooperation in preparing this work. We thank Dr. Luis Eduardo Roldán Arguello for his valuable collaboration in reviewing the article.

\section{Conflicts of interest}

The authors declare that they have no conflicts of interest in the preparation of this work.

\section{Ethical disclosures}

Protection of human and animal subjects. The authors declare that no experiments were performed on humans or animals for this study.

Confidentiality of data. The authors declare that they have followed the protocols of their work center on the publication of patient data.

Right to privacy and informed consent. The authors have obtained the written informed consent of the patients or subjects mentioned in the article. The corresponding author is in possession of this document.

\section{References}

1. Sanders J, Monogue M, Jodlowski T, Cutrell J. Pharmacologic treatments for coronavirus disease 2019 (COVID-19). A review. JAMA. 2020;2020:6019.

2. Zhu N, Zhang D, Wang W. China novel coronavirus investigating and research team. A novel coronavirus from patients with pneumonia in China, 2019. N Engl J Med. 2020;382:727-33.
3. Soto-Abraham V, Soriano-Rosas J, Díaz-Quiñonez A, Silva-Pereyra J, Vázquez-Hernández $P$, Torres-López $O$, et al. Pathologic changes associated with the 2009 pandemic influenza a $(\mathrm{H} 1 \mathrm{~N} 1)$ virus. N Engl J Med. 2009;361:2001-3.

4. Kaletra (Lopinavir/Randritonavir). North Chicago, IL: Abbvie; 2019. Available from: https://www.accessdata.fda.gov/drugsatfda_docs/label/2019/021226s048lbl.pdf. [Last accessed on 2020 Mar ${ }^{17}$.

5. Kevin C, Sanjay WH, Chunxue CB, Rello J. On Behalf of the International Task Force on COVID-19. COVID-19: interim Guidance on Management Pending Empirical Evidence. From an American Thoracic Society Led International Task Force. Covid-19-guidance. ATS; 2020.

6. Blakely BR, Rousseaux CG. Effect of ivermectin on the immune response in mice. Am J Vet Res. 1991;52:593-5.

7. Savanur NH, Honnegowda G, Krishnappa, Shastri KN, Narayana KK Effect of ivermectin on lymphocyte status in rabbit. Indian Vet $\mathrm{J}$. 1996;73:501-3.

8. Lim WS, van der Eerden MM, Laing R, Boersma WG, Karalus N, Town GI, et al. defining community acquired pneumonia severity on presentation to hospital: an international derivation and validation study. Thorax. 2003;58:377-82.

9. Masihi KN. Fighting infection using immunomodulatory agents. Expert Opin Biol Ther. 2001;1:641-53.

10. Mulcahy G, Quinn PJ. A review of immunomodulators and their application in veterinary medicine. J Vet Pharmacol Ther. 1986;9:119-39.

11. Lievano-Triana MJ, Osorio-Gómez NW, Olaya-Sánchez A, París SA. Electrocardiograma en pacientes con SARS-CoV-2. Guía rápida para interpretación. Repert Med Cir. 2020;29:1-9.

12. Gautret $P$, Lagier JC, Parola $P$. Hydroxychloroquine and azithromycin as a treatmentofCOVID-19: results of an open-label non-randomized clinical trial. Int J Antimicrob Agents. 2020;2020:105949.

13. Chen J, Liu D, Liu L. A pilot study of hydroxychloroquine in treatment of patients with common coronavirus disease-19 (COVID-19). Zhejiang Da Xue Xue Bao Yi Xue Ban. 2020;49:215-9.

14. Hydroxychloroquine. Hudson, OH: Lexicomp Inc.; 2016. http://www.online.lexi.com. [Last accessed on 2020 Mar ${ }^{17}$.

15. Savarino A, Boelaert JR, Cassone A, Majori G, Cauda R. Effects of chloroquine on viral infections: an old drug against today's diseases? Lancet Infect Dis. 2003;3:722-7.

16. Plaquenil (Hydroxychloroquine Sulfate). St Michael, Barbados: Concordia Pharmaceuticals Inc.; 2018. https://www.accessdata.fda.gov/drugsatfda docs/label/2019/0097680rig1s051lbl.p df. [Last accessed on 2020 Mar ${ }^{17}$.

17. Chloroquine. Hudson, OH: Lexicomp Inc.; 2016. http://www.online.lexi. com. [Last accessed on 2020 Mar $^{17}$.

18. Aralen (Chloroquine Phosphate). Bridgewater, NJ: Sanofi-Aventis; 2008. https://www.accessdata.fda.gov./drugsatfda_docs/label/2018/006002s045lbl.pdf. [Last accessed on 2020 Mar ${ }^{17}$

19. Esteves-Jaramillo A, Omer S, Gónzalez-Diaz E, Salmón D, Hixson B, Navarro-Reynoso F, et al. Acceptance of a vaccine against novel influenza a $(\mathrm{H} 1 \mathrm{~N} 1)$ virus among health care workers in two major cities in Mexico. Arch Med Res. 2009;40:705-11.

20. Navarro-Reynoso FP. El futuro de mi especialidad. Evolución de la neumología y su posicionamiento en los próximos 20 años. Rev Facult Med. 2010;53:32-4.

21. Navarro-Reynoso FP, San Román-Bonfil JM, Loera-Cervantes S, Ovalle-Narváez I, García-Flores M, Apaez-Olguín I, et al. Programa "Cirugía Segura Salva Vidas": Seguimiento por vía telefónica a pacientes intervenidos quirúrgicamente en el servicio de Cirugía General del Hospital General de México. Rev CONAMED. 2011;16:59-64.

22. Navarro-Reynoso FP. Editorial. Un cuadrángulo virtuoso, complemento de la atención médica. Rev Hosp Gen Méx. 2010;73:211.

23. Navarro-Reynoso FP. El hospital general de México, a la vanguardia en el cuidado de la vida. Rev Hosp Gral Méx. 2009;72(1):5-6.

24. Rodrigo C, Leonardi-Bee J, Nguyen-Van-Tam J, Lim WS. Corticosteroids as adjunctive therapy in the treatment of influenza. Cochrane Database Syst Rev. 2016;3:CD01040.

25. García-Hernandez M. Efecto Inmunomodulador de Ivermectina y Dietilcarbamacina en Ratones Infectados con Nocardia brasiliensis. Tesis de Maestría. Tutor: Dr. Carlos E. Medina de la Garza. Departamento de Inmunología, Facultad de Medicina y Hospital Universitario, Dr. José Eleuterio González, de la Universidad Autónoma de Nuevo León.

26. Masihi KN. Inmuno modulatory agents. Int $\mathrm{J}$ Antimicrob Agents. 2000;14:181-91.

27. Pell JM, James S. Immuno-enhancement and inhibition of GH-releasing factor by site directed anti peptide antibodies in vivo and in vitro. J Endocrinol. 1995;146:535-41.

28. Barton L, Duval E, Stroberg E, Ghosh S, Mukhopadhyay S. CoVid-19 autopsies, Oklahoma, USA. Am J Pathol 2020:153:725-33.

29. Osborn M, Lucas S, Stewart R, Swift B, Youd E. Briefing on CoVid-19. Autopsy Practice Relating to Possible Cases of CoVid-19 (2019-nCov, Novel Coronavirus from China 2019/2020). The Royal College of Pathologists; 2020.

30. Available from: https://www.covid-19.seth.es/wp-content/uploads/2020/04/ Recomendaciones- sobre-profilaxis-ETV-en- embarazo-y-puerperio-COVID-19.pdf. 